\title{
Potencial turístico del patrimonio cultural de la ciudad de Texcoco
}

DOI: 10.22403/UQROOMX/TYP05/26

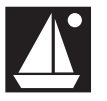

Resumen

Martha Marivel Mendoza Ontiveros, José de Jesús Ramírez Reyes, María Verónica Ruiz Conde, Pino Rodríguez Huerta, Esther Figueroa Hernández* Vicente Manuel Zapata Hernández ${ }^{* *}$

El objetivo fundamental de este trabajo es sentar las bases para la elaboración de estrategias turísticas coherentes y viables que contribuyan a la revaloración del patrimonio endógeno de la ciudad de Texcoco, especialmente el patrimonio natural y cultural, y que propicien que la población local tome parte en la salvaguarda de los recursos culturales y su identidad, y participe en la solución de los conflictos que plantea el uso turístico de los recursos.

Palabras $\mid$ Texcoco, desarrollo territorial, participación social, patrimonio, CLAVE $\mid$ turismo.

*Centro Universitario UAEM Texcoco, marivelmo@hotmail.com / investigacionturismo@yahoo.com.mx

**Universidad de La Laguna,Tenerife, España / vzapata@ull.es 


\section{Introducción}

En el marco del proyecto Texcoco:turismo, patrimonio y desarrollo local se planteó la necesidad de realizar una investigación básica e integral del patrimonio cultural de la ciudad de Texcoco. Como primera etapa se realizó un inventario de sus recursos patrimoniales; se consignaron su localización, uso y estado actual, datos históricos y régimen de propiedad, de esta etapa se obtuvo un diagnóstico de la situación o análisis FODA (fortalezas, oportunidades, debilidades y amenazas) del patrimonio, es decir, con los elementos para dimensionar su problemática para su uso turístico. El diagnóstico proporcionó un panorama general de las acciones que se deberán seguir para la planeación turística.

Se partió del supuesto de que la presencia de recursos en un área concreta no es una condición suficiente para que se origine y mantenga un proceso de desarrollo, aunque sí un requisito, pues si esos recursos no se utilizan de manera adecuada en el marco de una estrategia coherente, no se alcanzará una solución satisfactoria que permita superar una problemática existente. Como en muchos otros lugares, en Texcoco desatacó el abandono de los recursos patrimoniales, dispersos por el territorio, se encontraron sin señalización, carentes de toda protección, olvidados y desconocidos, incluso por la población local.

Para transformar este contexto, debe insertarse la promoción de los recursos en una estrategia global de desarrollo económico y social, en la que se delimite con claridad la utilización de todos los factores productivos. No obstante, por cuestiones de espacio, sólo se presenta aquí la parte referente al patrimonio.

Los recursos endógenos: infraestructura, equipamiento, aspectos de índole tecnológico y económico financiero, el patrimonio natural, así como el capital humano y sociocultural, constituyen elementos fundamentales en cualquier proceso de desarrollo, siempre y cuando estén integrados de forma adecuada, se ajusten a las características específicas de cada espacio y se complementen e interactúen con el resto de los elementos existentes en el contexto local.

\section{La ciudad de Texcoco y su patrimonio cultural}

Texcoco de Mora, cabecera del municipio Texcoco, se ubica al este de la cuenca de México, al pie del monte de la Sierra Nevada y a unos veintiséis 
kilómetros del Distrito Federal. Su altura promedio es de $2250 \mathrm{msnm}$. Es considerada como una pequeña ciudad de crecimiento urbano constante; el censo del año 2000 registró 53832 habitantes. La ciudad de Texcoco es el centro comercial, financiero, educativo y de servicios de la región.

De su origen prehispánico y su pasado colonial dan cuenta su patrimonio arqueológico y su arquitectura de los siglos XVII, XVIII y XIX; por su configuración indígena, cuenta con una riqueza patrimonial intangible que se manifiesta en fiestas patronales, gastronomía, danzas, música, mitos y leyendas, costumbres y tradiciones.

No obstante el elevado número y riqueza de sus recursos patrimoniales, los habitantes de Texcoco los desconocen y no los valoran, lo que da lugar a actividades vandálicas que deterioran ese patrimonio.

Por otra parte, el municipio recibe una gran afluencia de visitantes en la ex hacienda Molino de Flores, y el principal motivo de desplazamiento sigue siendo la gastronomía y la Feria Internacional del Caballo en los meses de marzo y abril.

\section{Metodología}

Se identificaron y documentaron los principales rasgos con potencial interpretativo localizados en la cabecera municipal de Texcoco, recurriendo a diversas fuentes de información primarias (reconocimiento del territorio y entrevistas a los vecinos de la ciudad Texcoco, así como a investigadores)' y secundarias (libros, revistas, planes de desarrollo, monografías municipales, tesis). Inicialmente el área se dividió en cuadrantes para facilitar la labor de los grupos de trabajo y ofrecer propuestas particulares por temáticas identificadas. La información recabada se organizó a partir de fichas de recursos (rasgos con potencial interpretativo).

Para la realización de estos trabajos se contó con la participación de estudiantes de la licenciatura en Turismo, del Centro Universitario de la Universidad del Estado de México, Texcoco.

'El directorio de estos investigadores forma parte de los productos de este trabajo. 
Potencial turístico del patrimonio

cultural de la ciudad de Texcoco

Diagnóstico

DiagnÓSTICO DE LA SITUACIÓN (FODA)

\begin{tabular}{|c|c|}
\hline Fortalezas & ades \\
\hline \multirow{2}{*}{$\begin{array}{l}\text { - Las obras de rescate y restauración } \\
\text { emprendidas por el Ayuntamiento }\end{array}$} & - Falta de señalética y señali \\
\hline & - La constante aparición de grafitis \\
\hline \multirow{6}{*}{$\begin{array}{l}\text { - La atención constante de la } \\
\text { Dirección de Desarrollo Urbano } \\
\text { Municipal ante la aparición de } \\
\text { grafitis } \\
\text { - La presencia de investigadores } \\
\text { e instituciones que hacen trabajo } \\
\text { de rescate e histórico }\end{array}$} & \\
\hline & \\
\hline & de los sitios arquitectónicos \\
\hline & \\
\hline & \\
\hline & - El ir \\
\hline \multirow{3}{*}{$\begin{array}{l}\text { - La existencia de un vasto } \\
\text { material documental sobre el } \\
\text { patrimonio arqueológico }\end{array}$} & \\
\hline & $\begin{array}{l}\text { fificios y } \\
\text { los hu- }\end{array}$ \\
\hline & mos \\
\hline \multirow{4}{*}{$\begin{array}{l}\text { - Presencia de restaurantes } \\
\text { de comida típica } \\
\text { - Existen personas que aún recuer- } \\
\text { dan la historia de las primeras calles } \\
\text { y de las casas antiguas }\end{array}$} & $\cdot \mathrm{L}$ \\
\hline & \\
\hline & $\begin{array}{l}\text { nio a } \\
\text { las e }\end{array}$ \\
\hline & - $\mathrm{Cc}$ \\
\hline \multirow{2}{*}{$\begin{array}{l}\text { - Existe un vasto repertorio de } \\
\text { fotografías antiguas de Texcoco }\end{array}$} & \\
\hline & \\
\hline $\begin{array}{r}\text { - Fácil ac } \\
\text { Texcoc }\end{array}$ & $\begin{array}{l}\text { inad } \\
\text { del } €\end{array}$ \\
\hline \multirow{2}{*}{$\begin{array}{l}\text { - Recursos patrimoniales } \\
\text { catalogados por el INAH }\end{array}$} & $\cdot \mathrm{F}$ \\
\hline & - $\operatorname{Pr}$ \\
\hline $\begin{array}{l}\text { - Reubicación de vendedores } \\
\text { informales que permitió recuperar } \\
\text { el Jardín Municipal y varias calles } \\
\text { del centro de la ciudad }\end{array}$ & $\begin{array}{l}\text { a través de estantes, mostradores, } \\
\text { escaparates y exhibidores }\end{array}$ \\
\hline
\end{tabular}




\begin{tabular}{|c|c|}
\hline Fortalezas & Debilidades \\
\hline $\begin{array}{l}\text { - Colocación de alumbrado e } \\
\text { iluminación en los edificios } \\
\text { restaurados }\end{array}$ & $\begin{array}{l}\text {-Vehículos estacionados delante } \\
\text { de los edificios interfieren en su } \\
\text { contemplación }\end{array}$ \\
\hline $\begin{array}{l}\text { - Un componente cultural en } \\
\text { donde se percibe la presencia } \\
\text { del origen indígena náhuatl } \\
\text { - Supervivencia de algunos }\end{array}$ & $\begin{array}{l}\text { - Escaso conocimiento y valoración } \\
\text { por parte de la población local } \\
\text { - Sólo existe un punto de informa- } \\
\text { ción turística }\end{array}$ \\
\hline $\begin{array}{l}\text { ahuehuetes legendarios en las } \\
\text { inmediaciones de la ciudad }\end{array}$ & $\begin{array}{l}\text { - Acciones vandálicas contra el } \\
\text { alumbrado e iluminación de los }\end{array}$ \\
\hline $\begin{array}{l}\text { - Fuerte presencia de un } \\
\text { patrimonio industrial y artesanal }\end{array}$ & edificios remodelados \\
\hline \multicolumn{2}{|l|}{ - Reconocida gastronomía local } \\
\hline $\begin{array}{l}\text { - Fiestas y celebraciones } \\
\text { prestigiadas motivan la } \\
\text { participación de los visitante }\end{array}$ & \\
\hline
\end{tabular}

\begin{tabular}{|c|c|}
\hline Amenazas & Oportunidades \\
\hline $\begin{array}{l}\text { - Falta de un proyecto de desarrollo } \\
\text { turístico integral en el municipio } \\
\text { de Texcoco }\end{array}$ & $\begin{array}{l}\text { - Presencia de diferentes entidades } \\
\text { interesadas en el patrimonio y en } \\
\text { temas de turismo }\end{array}$ \\
\hline $\begin{array}{l}\text { - Aunque hay interés, las autorida- } \\
\text { des municipales no logran dimen- } \\
\text { sionar el papel que deben desem- } \\
\text { peñar en el desarrollo turístico } \\
\text { - Insuficiente oferta de hospedaje } \\
\text { y de baja calidad }\end{array}$ & $\begin{array}{l}\text { - Posibilidad de que se integre } \\
\text { un colectivo conformado por el } \\
\text { Ayuntamiento, las universidades } \\
\text { de Texcoco, iniciativa privada y } \\
\text { asociaciones civiles, que gestionen } \\
\text { el desarrollo turístico }\end{array}$ \\
\hline $\begin{array}{l}\text { - Si no se regula el flujo turístico } \\
\text { puede ser factor de deterioro } \\
\text { del patrimonio }\end{array}$ & $\begin{array}{l}\text { - Entidades interesadas en la crea- } \\
\text { ción de un museo arqueológico } \\
\text { de Texcoco }\end{array}$ \\
\hline
\end{tabular}




\begin{tabular}{ll}
\hline \multicolumn{1}{c}{ Amenazas } & \multicolumn{1}{c}{ Oportunidades } \\
\hline - Que no se mantenga el actual & - Que el proyecto crezca al ir \\
Plan de Desarrollo Urbano y que & integrando el patrimonio que se \\
se permita el cambio de uso de & localiza en varias comunidades del \\
suelo en la periferia de la ciudad & municipio de Texcoco \\
de Texcoco & - La presencia de proyectos de \\
- La creación de una nueva planta & turismo rural y ecoturismo con lo \\
hotelera, restaurantera o de & que se diversificaría la oferta del \\
edificios comerciales para satis- & municipio \\
facer la demanda turística puede & - La rehabilitación y renovación del \\
implicar la pérdida indiscriminada & patrimonio edificado puede ayudar \\
de elementos de carácter histó- & a preservar la identidad y mejorar \\
rico o modificaciones sustanciales & la calidad de vida de la comunidad \\
a la configuración urbana & local \\
- El entorno natural de la ciudad & - Creación de nuevos empleos \\
de Texcoco no se ha cuidado & relacionados con la actividad \\
- Inadecuada infraestructura de & turística \\
recepción o acogida (estaciona- & - Dinamización de actividades \\
mientos insuficientes si se & económicas que se encuentran \\
incrementa el número de visitan- & en riesgo de desaparición (pro- \\
tes y reducidos para dar cabida & ducción artesanal, horticultura, \\
a autobuses) & floricultura, lechera, etcétera) \\
& - Existencia de edificaciones \\
& antiguas a las que se les puede dar \\
& un uso alternativo: información \\
& turística, centro de interpretación \\
& Posibilidad de promoción por ser \\
& ilustres personajes famosos e \\
\hline
\end{tabular}

Con esta información se procedió a identificar la situación actual de cada uno de los cuadrantes, a partir de lo que ofrecen y lo que se requiere para la planeación turística. 
ANÁLISIS POR CUADRANTES

\begin{tabular}{|c|c|c|}
\hline $\begin{array}{c}\text { Cuadrante / } \\
\text { barrio }\end{array}$ & Se ofrece & Se requiere \\
\hline \multirow[t]{3}{*}{$\begin{array}{l}\mathrm{I}^{\circ} / \text { Barrio de } \\
\text { San Mateo }\end{array}$} & Comercio informal & $\begin{array}{l}\text { Reordenamiento del } \\
\text { comercio }\end{array}$ \\
\hline & Intenso tráfico vehicular & $\begin{array}{l}\text { Reubicación de las } \\
\text { terminales de transporte } \\
\text { público }\end{array}$ \\
\hline & Zona habitacional popular & \\
\hline \multirow[t]{2}{*}{$\begin{array}{l}2^{\circ} / \text { Barrio de } \\
\text { San Pablo }\end{array}$} & $\begin{array}{l}\text { Centros comerciales, de } \\
\text { diversión y entretenimien- } \\
\text { to, hotel y restaurantes }\end{array}$ & $\begin{array}{l}\text { Ordenamiento para } \\
\text { controlar los anuncios } \\
\text { publicitarios }\end{array}$ \\
\hline & Intenso tráfico vehicular & $\begin{array}{l}\text { Reubicación de las termi- } \\
\text { nales de transporte público } \\
\text { y restricciones para el esta- } \\
\text { cionamiento en las calles }\end{array}$ \\
\hline \multirow{4}{*}{$\begin{array}{l}3 \% \text { Barrio de } \\
\text { San Juanito y } \\
\text { el Carmen }\end{array}$} & $\begin{array}{l}\text { Zona arqueológica y sitios } \\
\text { históricos de la Conquista }\end{array}$ & $\begin{array}{l}\text { Señalización, información y } \\
\text { servicios complementarios }\end{array}$ \\
\hline & $\begin{array}{l}\text { Zona comercial, hotel y } \\
\text { servicios de alimentos } \\
\text { y bebidas. }\end{array}$ & $\begin{array}{l}\text { Ordenamiento para } \\
\text { controlar los anuncios } \\
\text { publicitarios }\end{array}$ \\
\hline & Zona habitacional & \\
\hline & $\begin{array}{l}\text { Arquitectura civil y reli- } \\
\text { giosa de los siglos XVI, XVII } \\
\text { y XVIII }\end{array}$ & $\begin{array}{l}\text { Continuar y ampliar el } \\
\text { mantenimiento y la limpie- } \\
\text { za de este patrimonio: } \\
\text { señalización, información y } \\
\text { servicios complementarios. }\end{array}$ \\
\hline
\end{tabular}

(Continúa) 
Potencial turístico del patrimonio

cultural de la ciudad de Texcoco

ANÁLISIS POR CUADRANTES

(Continuación)

\begin{tabular}{lll}
\hline \multicolumn{1}{c}{$\begin{array}{c}\text { Cuadrante/ } \\
\text { Barrio }\end{array}$} & \multicolumn{1}{c}{ Se ofrece } & \multicolumn{1}{c}{ Se requiere } \\
\hline $4^{\circ}$ / Barrio de & Zona habitacional & Mantener el uso \\
San Pedro & principalmente & habitacional \\
& Escasa presencia de & \\
& recursos patrimoniales & \\
& Pocos comercios & \\
\hline
\end{tabular}

Del análisis se desprende que los cuadrantes que concentran la mayoría de los recursos patrimoniales, los servicios de alimentos y bebidas, hospedaje, centros de diversión y entretenimiento son el $2^{\circ}$ y el $3^{\circ}$, que además incluyen el Jardín Municipal, el mercado San Antonio y la Catedral, de ahí que las estrategias planeadas deban comenzar en ellos.

A partir de estos primeros resultados, se puede establecer que la vocación turística de la ciudad de Texcoco es el turismo cultural. Lamentablemente, su patrimonio es desconocido no sólo por el visitante sino también por la comunidad local, $y$ hay que recordar que para que el turismo sea un dinamizador del espacio y de la comunidad, ésta debe involucrarse en el desarrollo y aprovechamiento del potencial turístico del lugar, por lo cual es indispensable plantear estrategias que permitan su incorporación en lo turístico, sin obstruir o cambiar su actividad productiva, es decir, el turismo debe complementar las actuales actividades productivas y no desplazarlas, ya que propiciar la dependencia a una actividad económica tan volátil como el turismo es arriesgado.

Asimismo, esta ciudad se puede convertir en un polo de difusión y promoción de su entorno, de modo que muchos visitantes estén alojados en ella pero realicen sus actividades en la ciudad y en su entorno más próximo, pero también tengan la posibilidad de acudir a otros atractivos menos cercanos, como el Distrito Federal o las pirámides de Teotihuacan, entre otros. Ese potencial, dado por su localización y dimensión de ciudad agradable para un visitante, no debe perderse de vista, sobre todo a la hora de atraer a visitantes que se sienten más a gusto en ciudades pequeñas o intermedias, fuera de las grandes aglomeraciones. 
La vocación turística identificada en la ciudad de Texcoco hace indispensable caracterizar e interpretar su patrimonio cultural para primero motivar su conocimiento entre la población local y ésta lo enseñe luego a los visitantes, lo cual reforzará la identidad texcocana y comprometerá a los residentes con el cuidado y conservación de sus recursos culturales. Una comunidad no debe desear el turismo sólo por los beneficios económicos que les puede reportar, sino también porque se sientan orgullosos de su patrimonio y quieran compartirlo. Ello nos lleva a concebir al turismo de manera diferente: aquella comunidad hará el mejor uso de sus recursos y ofrecerá a sus visitantes una experiencia gratificante y llena de significado.

No obstante, no se trata de la venta de cultura, sino de que se valoren y aprecien los recursos, tanto por parte de los visitantes como por parte de la comunidad local.Si se apuesta sólo a la turistización, entendida como un incremento constante en el número de visitantes, se asumen demasiados riesgos para un recurso valioso, frágil y no renovable. La "venta de patrimonio" debe tener sus límites, los de su capacidad de carga; si se desarrollan acciones pensando exclusivamente en la afluencia turística puede llevar a cualquier destino a un escenario de insostenibilidad. Una afluencia excesiva, muchas veces sin control, es susceptible de generar el deterioro del componente físico del patrimonio y, sobre todo, de incidir negativamente sobre su dimensión simbólica y funcional. La maquinaria turística puede aplastar el patrimonio y la propia identidad cultural del territorio si alcanza proporciones masivas.

De ahí la necesidad de reflexionar en que la práctica turística en un recurso patrimonial conlleva dimensiones tanto positivas como negativas, plantea nuevos problemas que tienen que ver con el equilibrio funcional, la gestión de los flujos turísticos, la planificación urbanística, la protección del patrimonio, la accesibilidad y movilidad, el medioambiente urbano, la creación de productos turísticos y todo lo que implica el desarrollo sostenible.

A partir de lo expuesto, es posible pensar en nuestra herencia cultural desde un enfoque sustentable como todo bien heredado que se puede someter a diversos usos, a condición de que se entregue debidamente conservado, inventariado, enriquecido y difundido, a las generaciones futuras, las cuales se encargarán de aplicar a su manera la conceptualización de esta herencia y su adecuada gestión a las personas que vendrán después. De esta forma, una estrategia para mantener y compartir nuestra herencia cultural es el turismo 
sustentable, pero para ello debemos elaborar el producto turístico en función de los recursos (Martín, 2006).

Para que las promesas de la relación turismo/patrimonio se cumplan es necesario incorporar un modelo de desarrollo turístico sostenible a nivel micro. El aprovechamiento del patrimonio como recurso turístico sólo se puede realizar sobre la base de su consideración prioritaria como recurso cultural; ya que su banalización puede ser tan peligrosa como el deterioro físico. Asimismo, la incorporación de la población local en todos los pasos y niveles de la planeación es fundamental, no es posible hablar de desarrollo turístico sostenible si los agentes locales no tienen el control del perfil turístico de su comunidad y capacidad para impedir que agentes externos controlen las acciones movidos por intereses ajenos al desarrollo local. Lo anterior exige la necesidad de estudiar y conocer el patrimonio cultural de Texcoco para hacer una planificación adecuada, previa a su promoción y al aprovechamiento sostenible.

Al momento de definir la planificación, hay que ser muy cuidadosos para determinar el papel que jugará el patrimonio cultural. No debemos perder de vista que son muy pocos los recursos patrimoniales que, por sí mismos, son capaces de atraer visitantes y a su vez son pocos los usuarios que se pueden calificar como estrictamente culturales.Antes bien, es mayor el número de personas que viajan para descansar o divertirse y que tropiezan con el patrimonio que está por ahí.A partir de este segundo escenario, debemos tener presente que la mayoría de los recursos son complementarios y que contribuyen a mejorar la imagen del territorio, lo que hace necesario que se engarcen en una estrategia de destino.Asimismo, conviene recordar, que en la llamada sociedad de consumo, los individuos buscan experiencias de ocio, por lo que dicha experiencia debe ser de calidad para un consumidor cada vez más exigente, que compara y elige su destino apostando por la calidad y no por la cantidad.

Así pues, el turismo se convierte en un motor de desarrollo cuando éste se apoya en un marco general de impulso del territorio y de la sociedad, para integrar y aprovechar oportunidades, estructuras y recursos desde los que es posible construir nuevas realidades productivas (Ávila y Barrado, 2005). Para alcanzar el desarrollo turístico equilibrado es necesario actuar sobre el conjunto de lo que significa un destino, entendido éste como un espacio físico y social con determinadas características y calidades que ofrece una yuxtaposición de valores ambientales, territoriales, sociales y culturales, cuyo 
conjunto lo convierten en algo que merece la pena experimentar, que ofrecerá una vivencia integral al visitante (Ávila y Barrado, 2005) y que sólo en ese lugar es posible disfrutar.

En este proceso, el primer paso es tener una estrategia de destino; lo cual implica construir una visión consensuada para el conjunto de la sociedad que habita y trabaja en dicho destino, tal visión debe estar en función de sus valores sociales, culturales y ambientales (Ávila y Barrado, 2005). Posteriormente, se debe desarrollar un plan operativo en el que se planteen acciones concretas, plazos y dotaciones presupuestales para lograr los objetivos.

Conclusiones del diagnóstico interno ${ }^{2}$

I. El conjunto patrimonial de la ciudad de Texcoco es de una importancia extraordinaria, sin embargo, para que pueda dar respuesta a las demandas y necesidades turísticas se debe acondicionar y gestionar. Tener patrimonio es importante pero no es suficiente para ser destino turístico de calidad. El patrimonio, para ser atractivo turístico, debe estar adecuadamente proyectado, tanto el edificio como su entorno, para la visita pública.

2. Actualmente el uso turístico se centra en el Jardín Municipal, el Mercado San Antonio y la Catedral, y aunque el visitante hace uso de modo espontáneo de otros puntos, lo hace sin ayuda de una señalización o información adecuadas.

3. Por lo anterior, es importante diseñar estrategias en torno al Jardín Municipal, el Mercado San Antonio y la Catedral para que se conviertan en nodos canalizadores hacia el resto de los puntos de interés que les circunda.

4. Convertir el "consumo" de la ciudad en una experiencia fácil y grata con nuevos contenidos, que atraiga a diversos públicos y genere la necesidad de repetir la visita requiere de la elaboración de productos específicos relacionados con las nuevas tendencias del turismo.

${ }^{2}$ Cabe aclarar que el diagnóstico aquí presentado contempla los estudios de la estructura turística y el de la actual demanda en la ciudad de Texcoco. 
5. Para la información del turista en la ciudad se debe contar con espacios, soportes y recursos humanos debidamente preparados.

6. La oferta de alimentos, bebidas y alojamiento debe consolidarse, siendo necesario reforzar su comercialización e incorporarse como parte del atractivo que ofrece Texcoco.

7. El comercio necesita sumarse a la oferta turística de la ciudad, mejorando sus establecimientos, diversificando su oferta y promoción hacia los turistas.

8. La complejidad de la ciudad de Texcoco como destino turístico y la multiplicidad de agentes que deben intervenir en él exige estructuras de coordinación y de gestión que ayuden a estructurar un producto global, mientras este órgano se crea, el Plan de Desarrollo Municipal deberá promover las primeras acciones de coordinación.

9. Debe valorarse la posibilidad de crear un foro permanente conformado por especialistas que, a modo de observatorio, evalúen periódicamente la labor del Plan de Desarrollo o del sector turístico en general.

10. Una de las labores ineludibles que debe afrontarse es la capacitación del recurso humano a través de una adecuada formación mediante el diseño de un programa a corto y a largo plazo con los diferentes sectores.

\section{Plan de Desarrollo Turístico de Texcoco}

Hacer de la ciudad de Texcoco un destino para la práctica del turismo cultural, con productos innovadores que inciten la valoración y el aprecio por el patrimonio cultural.

Esta visión se apoya en tres ejes:

- Un patrimonio dinámico que cristalice en una ciudad segura, limpia y acogedora

- Calidad integral en la oferta

- Fórmulas de gestión del turismo innovadoras 
Líneas estratégicas del Plan de Desarrollo Turístico de Texcoco

a) Estrategias referidas al producto

- Potenciar el patrimonio cultural como producto turístico a través de rutas interpretativas temáticas

- Impulso y mejoramiento de la presentación del patrimonio de la ciudad

- Dotación y mantenimiento de la infraestructura

- Coordinación y mejoramiento de la planta turística

b) Estrategias de comercialización

- Coordinación de una oferta que atraiga al turista y al touroperador

c) Estrategias de promoción, comunicación y diseño de imagen

- Un producto de calidad debe ser presentado de modo innovador y diferenciado

d) Estrategias para el desarrollo de una estructura de gestión del turismo

- Articulación de entidades en equipos y fórmulas capaces de impulsar los cambios necesarios.

Una vez definidas las líneas estratégicas, se determinaron las acciones que deben desarrollarse en los tres primeros años de aplicación del Plan de Desarrollo Turístico de la ciudad de Texcoco sin perder de vista que tales acciones deben atender a criterios de oportunidad y consenso.Asimismo, debe tenerse siempre presente que el plan es flexible. De esta forma, los proyectos que se organizan en función de las líneas estratégicas seleccionadas son:

\section{I.Acciones referidas al producto}

I.I Una presentación novedosa del patrimonio mediante el desarrollo de los siguientes proyectos:

- Recuperación, mantenimiento y conservación del patrimonio

- Señalética

- lluminación

- Programas interpretativos

- Mobiliario urbano

- Cableado interno 
Potencial turístico del patrimonio

cultural de la ciudad de Texcoco

- Peatonalización del centro de la ciudad

- Museo

I.2 Recepción de visitantes

- Estacionamientos

- Ampliación y mantenimiento de vías de acceso y comunicación

- Información turística

- Código de conducta para visitantes

2. Diseño de imagen, promoción y comunicación

2.I Plan integral de comunicación

3. Comercialización

3.I Comercialización de una oferta atractiva

4. Desarrollo de estructuras de gestión del turismo

4.I Mejoramiento de la calidad de la oferta

Cada proyecto deberá contener una ficha sintética que incluya: descripción, proceso de implantación, agentes implicados, presupuesto, fórmula de financiamiento, plazo de ejecución y comentarios para operación.

\section{FUENTES CONSULTADAS}

Ávila Bercial, Reyes y Diego Barrado Timón (2005). "Nuevas tendencias en el Desarrollo de destinos turísticos: marcos conceptuales y operativos para su planificación y gestión”, en Cuadernos de turismo, núm. I5 [en línea], 27-43.

Martín, Marcelo (2006). "Patrimonio y sociedad. Interpretación y otras cuestiones en la planificación turística de las ciudades monumentales" [en línea]. España: Disponible en http//interpretaciondelpatrimonio.com, documentos [2007, febrero]. 


\section{NORMAS DE PUBLICACIÓN}

\section{"Leokila y preavils es una publicación que busca el análisis, crítica y reflexión de los temas de actualidad vinculados}

a las áreas de Turismo, Educación, Administración y Negocios, Lenguas, Informática y Recursos Naturales.

Teoría y Praxis se estructura de la siguiente manera:

ARTículos. Consisten en contribuciones académicas de los autores en las cuales se exponen también las de otros especialistas en el tema estudiado.

SECCIÓN DE NOTAS. En este apartado se publican reportes de investigación, reportes de conferencias, reportes sobre trabajos académicos o de tesis y otras notas elaboradas por instituciones públicas, privadas, asociaciones, académicos y estudiantes, que por su contenido sean relevantes y actuales.

\section{Instrucciones}

Los artículos deberán ser escritos en Word 2003 o anterior, en hojas tamaño carta, en una sola faz, espaciado sencillo, y los márgenes: superior 3.5, inferior 2.5, izquierdo 3.5, derecho 2.5. Extensión máxima, 5000 palabras ( 10 cuartillas). En la redacción, no se permite la utilización de la primera persona, sea en singular o plural mayestático. Los originales constarán de:

- Título del trabajo: máximo 12 palabras

- Autor(es), adscripción y dirección electrónica

- Resumen: máximo 250 palabras

- Palabras clave: cinco

- Texto: Introducción, antecedentes, metodología, resultados, discusión, una conclusión o comentario final, fuentes consultadas.

- Cuadros, gráficos y mapas serán incluidos en el texto; los mapas, deberán entregarse además en archivo de imagen con extensión jpg, tiff o eps, con una resolución de $300 \mathrm{dpi}$.

Las notas tendrán las mismas especificaciones técnicas. El cambio radica en la extensión, la cual no será mayor a 3000 palabras (seis cuartillas). 


\title{
Fuentes consultadas
}

- Las referencias citadas irán en el cuerpo del texto y se individualizarán entre paréntesis con el siguiente orden de datos: Autor, fecha: páginas (Palafox, 2003:15).

- Las referencias bibliográficas completas irán al final del artículo y conforme al siguiente modelo: Autor/editor (año de publicación). Título del libro (edición) (volumen). Lugar de publicación: editor o casa publicadora:

Luenberger, D. (1989). Programación lineal y no lineal. México:Addison-Wesley.

- Documentos electrónicos

Autor/responsable (fecha de publicación).Título (edición) [tipo de medio]. Lugar de publicación: editor. Disponible en: especifique la vía [fecha de consulta].

Hernández, M. E. (1998). Parque Nacional Canaima [en línea]. Caracas: Universidad Central de Venezuela. Disponible en: http://cenamb.rect.ucv. ve/siamaz/dicciona/canaima/canaima2.htm [2000, 3 de junio].

- Publicaciones periódicas

Autor (año de publicación). “Título del artículo”.Título de la revista, volumen (número de la edición), páginas.

Stefan, D. (1997). “Sociedades poscomunistas:Transición económica en los países de Europa central y Oriental”. Anales de la Universidad Metropolitana, vol. 4, 19-27.

Los artículos o notas de investigación deberán ser enviados impresos por triplicado y en formato digital, a la siguiente dirección:

\author{
Universidad de Quintana Roo \\ Unidad Académica Cozumel \\ Ave.Andrés Quintana Roo \\ esquina con 110 Sur \\ Col. San Gervasio \\ Cozumel, Quintana Roo \\ CP 77642 \\ teoriaypraxis@uqroo.mx
}

